This is a post-peer-review, pre-copyedit version of an article published in International Journal of Retail and Distribution Management. The final authenticated version is available online at: https://doi.org/10.1108/IJRDM-02-2020-0043

To cite this article:

Seghezzi, A. and Mangiaracina, R. (2020), "On-demand food delivery: investigating the economic performances", International Journal of Retail \& Distribution Management, Vol. 49 No. 4, pp. 531-549. https://doi.org/10.1108/IJRDM-02-2020-0043

\title{
On-Demand Food Delivery: investigating the economic performances
}

\author{
Abstract \\ Purpose - This paper focuses on On-Demand Food Delivery (ODFD), i.e. the delivery \\ of fresh prepared meals to customers' homes, enabled by the use of online platforms. In \\ ODFD, a key process is represented by last-mile deliveries: they directly affect \\ customers (the delivery price influences their purchase intention), riders (the \\ compensation drives their willingness to perform deliveries) and platforms (deliveries \\ are very expensive). In this context, this work aims to investigate the economic \\ performances of ODFD last-mile deliveries.
}

Design/methodology/approach - This study adopts a multi-method threefold process. First, it develops a model that - after the generation of customers' demand and the assignment of deliveries to available riders - identify incomes and costs faced by a ODFD operator. Second, the model is applied to a base case in Milan (Italy). Third, sensitivity analyses are performed (on daily demand and riders' salary).

Findings - The analyses allow - beside the identification of significant values associated to ODFD profitability - to draw general insights about delivery price (e.g. free delivery is not economically sustainable), daily demand (e.g. greater demand values do not only improve positive results, but also worsen negative ones) and fix/variable wage mix (e.g. increasing the variable wage enhances the profitability for platforms). 
Originality/value - On the academic side, this word enhances extant literature about ODFD, proposing a model - with multidisciplinary implications - to strategically investigate profitability conditions of last-mile deliveries. On the managerial side, it provides support for (logistics/marketing) ODFD practitioners, since it allows to evaluate the potential impact of significant decisions on profitability.

Keywords - On-demand food delivery, crowdsourcing logistics, last-mile delivery, ecommerce

Paper type - Research paper 


\section{Introduction}

Business-to-Consumer (B2C) e-commerce is fast spreading all over the world, in both mature and emerging markets. In 2019, online sales have been worth more than $€ 3,000$ billion worldwide. Focusing on Italy, B2C e-commerce has never stopped increasing, and - according to the Italian B2c eCommerce observatory (2019) - online transactions have reached $€ 31.6$ billion in 2019 ( $+15 \%$ with respect to the previous year). This growth is particularly high in the food and grocery industry $(+42 \%)$, and it is even higher if we consider online sales of fresh/prepared meals - the so called On-Demand Food Delivery $(+56 \%)$.

The traditional Food Delivery concept arose long before the diffusion of ecommerce, and its origin dates back to the World War II. At that time, a large part of the population did not have access to food or to equipment for cooking, and voluntary organisations managed to serve meals to those who needed. After the end of the war, from a social and public utility, it has progressively become a value-added service offered by restaurants to improve the quality of life: after placing an order, customers just have to wait for their meals to be home-delivered. By far, the most common food delivery model is the "traditional" one: orders are typically issued by phone to a local already-known restaurant, and the delivery is performed by a rider working for the restaurant.

However, as it happened in many other sectors, the rise of digital technologies has reshaped also the Food Delivery scenario. As a matter of fact, with the diffusion of the Internet, customers have become more and more used to online shopping. They purchase whenever they want and wherever they are, being provided with a clear instant view of many possible options with related prices. Hence, they tend to expect the same experience when it comes to ordering their lunch or dinner. As a result, the combination of the traditional FD concept and the rise of digital technologies has created a new 
flourishing business. Online ODFD platforms (e.g. Glovo, Swiggy, Deliveroo) "are expanding choice and convenience, allowing customers to order from a wide array of restaurants with a single tap on their smart phones" (Kapoor and Vij, 2018).

Beside the pre-sale and sale experiences, e-customers are becoming more and more requiring also with regard to the performances of a crucial logistics process: the last-mile delivery. This last stretch of the supply chain - aimed to deliver the parcels to the buyers' doorstep - is the direct interface between the company and the consumers, who have increasing expectations in terms of both service level and price (Xiao et al., 2018). On the one side, they ask for punctuality as well as (maybe more) for speed. In a business like the ODFD, being fast becomes essential: from the moment the order is issued, customers often expect to receive their meal in 40 minutes. If considering that the meal requires a 20-minute preparation, the delivery must typically be performed in 20 minutes. On the other side, since online shoppers are not willing to pay much for the delivery, price represents a fundamental factor to select the ODFD provider. Nonetheless, operators need to bear the costs associated to the workforce, and sometimes also to the transport mean. Hence, in order to offer low delivery prices, they need to improve the efficiency of their processes.

In the light of all these considerations, the profitability of last-mile deliveries in ODFD is a both crucial and critical issue. It is strongly linked to customers - as the delivery price influences their purchase intention (Yeo et al., 2017) - riders - since the compensation drives their willingness to perform deliveries (Qi et al., 2018) - and platforms - because deliveries are very expensive (Fikar et al., 2018). This being the context, this paper aims to address a key issue for ODFD operators (both wellestablished firms and new entrants): investigate the profitability conditions of last-mile deliveries of fresh prepared meals. 
The remainder of this paper is organised as follows: section 2 presents the results of the literature review, section 3 defines the research questions and the adopted methodologies, section 4 illustrates the model development, its application and the sensitivity analysis, and section 5 summarises the conclusions stemming from the work.

\section{Literature review}

Profitability of last-mile deliveries of fresh prepared meals may be seen as lying at the intersection of three main topics: (i) profitability of last-mile deliveries, (ii) crowdsourcing logistics and (iii) fresh prepared food. As a matter of fact, it deals with the profitability of the deliveries of fresh prepared meals from restaurants to customers' home, performed by a crowd of non-specialised workers (i.e. the "riders").

XXXXXXXXXXXXXXXXXXXXXXXXXXXXXXXXXXXXXXXXXXXXXXXXXXXXXXXXXXXXXXXXXXXXXX

Please take in Figure 1

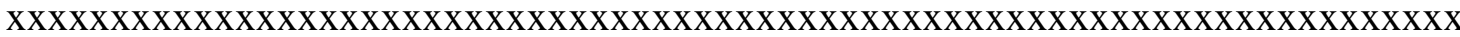

(i) Last-mile delivery (LMD) is the "last stretch" of the order fulfilment, aimed at delivering the products ordered online to the final consumers (Lim et al., 2018). For retailers operating online, it is very critical in terms of both customer satisfaction (effectiveness) and cost (efficiency). Accordingly, different academic works developing traditional retailing literature in the realm of e-commerce have highlighted how LMD is essential for e-retailers, and how poor logistics performances may undermine their success (Grewal et al., 2004). Considering effectiveness, LMD performances strongly influence the intention of customers to repeat purchases with the same retailer (Esper $e t$ al., 2003). Among the retailing service quality attributes proposed by Yang et al. (2003), a fundamental role is played by convenience, which allows the customer to 
access the ordered good in a timely, serviceable and flexible manner. As stated by the author, a key element of this measure concerns the physical delivery. Online buyers are very demanding in terms of quality of the service (Xu 2013), in particular referring to time performances: they expect their parcels to be delivered fast (i.e. short order cycle time), and exactly in the arranged time window (i.e. high punctuality) (Lu et al., 2016). Considering efficiency, LMD is the most expensive part of the delivery process: order dimension is typically very low - less than two lines per order and few pieces per line and destinations may be very dispersed (Macioszek, 2017). As a result, last-mile delivery cost may amount up to half of the overall logistic costs (Vanelslander et al., 2013). Based on these premises, on the one hand, customers are very demanding in terms of LMD performances; on the other hand, they are usually not willing to pay for such stringent logistic requirements (Borsenberger et al., 2016). As a result, the profitability of last-mile deliveries emerges as a very crucial issue for retailers operating online, which has been gaining the interest of the scientific community. Accordingly, academics have been striving, on the one side, to analyse the factors impacting LMD performances, and, on the other side, to find innovative solutions to improve them.

Among these solutions, different authors focussed on the exploitation of new technologies. In some cases they are applied to the delivery phase, as it happens with parcel lockers - i.e. boxes shared among different customers (Wang et al., 2014) - or roam delivery - i.e. the delivery in the trunk of the car (Reyes et al., 2017). In other cases, the technology is instead applied to the transport mean, as it happens with underground delivery - i.e. capsules containing parcels moving within an underground pipeline system (Slabinac, 2015) - drones - i.e. unmanned aerial vehicles in which parcels are loaded (Ha et al., 2018) - and robots - i.e. self-driving road vehicles (Boysen et al., 2018). Other research efforts focussed instead on the use of "digital" 
technologies (e.g. mobile apps and online platforms). They are seen as enablers that may improve the last-mile delivery process, thanks to the possibility to exploit advanced potentialities. Among them, there are geo-localisation services and the possibility to perform real-time order collection (Rai et al., 2017; Rougès and Montreuil, 2014; Schreieck, et al., 2016).

(ii) One promising LMD solution that relies on the use of digital technologies, which is supported by different authors in the logistics field, is crowdsourcing logistics. In general, crowdsourcing consists in outsourcing internal activities to a network of "common" people, i.e. the "crowd". Literature addressing crowdsourcing logistics in retailing has been expanding, and this promising solution has been explored in many different contexts. The crowd may be involved during the generation of new ideas, the initial and creative phase of the new product development process (Wu et al., 2017). It may provide its contribution during the design phase of new products, ensuring companies not to neglect characteristics and features that are important to customers (Allen et al., 2018). Sometimes people of the crowd plays their role after the purchase, thanks to the rating and reviews about the products or service they bought (Ghose et al., 2012). In some cases, retailers can also benefit from a customer-to-customer support, based on forums and blogs through which buyers offer mutual support based on their prior experience (Kleemann et al., 2008). With reference to logistics, the application of crowdsourcing to last-mile deliveries implies assigning the delivery phase to people from the crowd who, on a voluntary basis, become responsible for bringing the parcels to the final customer's door (Carbone et al., 2017).

This logistics model allows to gain significant benefits for all the involved stakeholders (Rai et al., 2017). The crowd has the possibility to earn extra incomes from flexible work (Vecera and Pribyl, 2017). Indeed, deliveries are often performed by 
people who have to move on a similar route for personal/working reasons (Wang et al., 2016). Companies selling online may rely on a source of competitive advantage, since this model typically entails lower shipping cost (Chen et al., 2014). As a matter of fact, it implies saving for e-retailers, as the crowd (composed by not-specialised workers) could offer the delivery service at lower prices than couriers (Carbone et al., 2017). Finally, customers are offered higher delivery speed, higher flexibility and value-added services such as real-time tracking (Rougès and Montreuil, 2014), thus improving both efficiency and effectiveness performances. Though, a crucial element that may hinder to reach these benefits is the availability of the riders. One key aspect - due to its strong impact on both the number of available riders and the profitability of crowdsourcing logistics initiatives - is the compensation offered to the crowd. Some works supported paying a fixed salary, while other recent contributions highlighted the importance of considering not only the fixed part, but also a variable one (Wang et al., 2016; Chen et al., 2018), thus remunerating riders both based on the delivery accomplishment and on the travelled distance (Arslan et al., 2018; Qi et al., 2018). Still, an agreement of academics about the theme seems to be missing, and the suitability of these alternatives may depend upon the specific implementation context (e.g. industry, legal constraints).

(iii) Many of the works concerning both the profitability of LMD and crowdsourcing logistics do not focus on one specific sector, but they address generic "parcels". Though, despite the management of last-mile logistics is crucial for all B2C online players, some products, such as food, have very peculiar criticalities. Among the different businesses linked to the diffusion of online sales of food products, a novel and disruptive one is On-Demand Food Delivery, i.e. the delivery of fresh prepared meals to customers' homes, enabled by the use of online platforms (Fikar et al., 2018). The birth of such business has marked a momentous change in the food retailing scenario, which 
may be read in the light of different theoretical perspectives. According to Brown (1987), it is possible to classify the multiple theories explaining retail changes in three main clusters: environmental theory, cyclical theory and conflict theory. As per the environmental theory, changes in retail are due to a change in the environment in which they operate (Roth and Klein, 1993). Among the different factors - i.e. changes in consumer characteristics, technology and competition - the technological element, and more in detail the rise of the Internet, is certainly the predominant one - as well as the enabler - for the birth of the ODFD business. According to the conflict theory, retail innovation does not lead to a reduction of the number of retail formats, but, on the contrary, it entails the creation of completely new businesses (Markin and Duncan, 1981). In a retailing context in which the two predominant options for a customer to eat were either cooking a home-prepared meal or turning to a single restaurant, an online platform that allows to order from a wide assortment of alternative places offering a great variety of home-delivered meals has certainly reshaped the existing context (Kapoor and Vij, 2018). Considering instead the cyclical theories - among which a seminal thesis is that of the "Wheel of retailing" - there is a clear cyclical pattern of evolvement followed by retailers, which go through defined phases (Hollander, 1960). Despite there are many different applications of cyclical theories, the academic community has been questioning its suitability to some new environments, and different evolutions have been proposed in many directions. As stated by Sheth (2020), retailing follows a clear evolution path, based on what it offers to customers. Starting from the more traditional "location" and "convenience" values, switching to a full "customer experience", retailers will progressively move towards the provision of integrated valueadded services, as it is happening with ODFD. Independently from the considered theory, both the academic and the managerial community recognise how the birth of 
ODFD has been tremendously changing the food retailing scenario.

Despite the significance of such business, academic literature about ODFD is still at early stages, due to the novelty of the business (Zambetti et al., 2017). The majority of the authors treated organisational and legal issues, linked to the employment and working conditions of the riders (e.g. Fleming, 2017; Klumpp and Ruiner, 2018). Few contributions may instead be found addressing the management of logistics. Some of them focussed on the design of the distribution network, i.e. the definition of the location and the number of riders' departing points (Zambetti et al., 2017). When dealing with LMD, Fikar et al. (2018) proposed the adoption of urban transhipment points to transfer orders from one vehicle to another, and to consolidate multiple shipments. Though, as stated by the authors, consolidation points require high demand (thus the possibility to aggregate different orders) and indifference of customers about the source from which the order is fulfilled (e.g. different branches of the same restaurant). This model well fits contexts in which the On-Demand Food Delivery is already widespread. Still, there are several countries - such as Italy or France - that are different, and in which the conditions for introducing consolidation points are still not met. On the one side, On-Demand Food Delivery - even if growing - is still at an embryonal phase, and the delivery density is thus very low. On the other side, specifically considering the Italian context, the large majority of the restaurants are not part of bigger chains, and consumers do often explicitly select the specific restaurant to issue their orders. Therefore, in contexts such as the Italian one, ODFD deliveries are one-to-one, meaning that the rider collects one order and delivers it to a single customer destination (Zambetti et al., 2017).

Based on the above, LMD is a crucial process, and profitability performances are very critical. This is particularly true if considering the specificities of the food 
sector, and even more of fresh prepared meals (Kapoor and Vij, 2018). In such a context, the implementation of crowdsourcing logistics could lead to significant benefits in terms of LMD performances. Nonetheless, while the three mentioned fields (i.e. profitability of LMD, crowdsourcing logistics, ODFD business) were addressed by different scientific works - both singularly considered and combined in pairs - the intersection of all of them (i.e. the profitability of last-mile deliveries in the ODFD business) is still under-investigated (see Figure 1). Accordingly, there is much space for research efforts aimed at investigating (i) the profitability of last-mile deliveries (ii) outsourced to a crowd of not-specialised people, i.e. the riders, (iii) of fresh prepared meals (in the so-called ODFD business).

\section{Objectives and methodology}

The review of the literature revealed that, due to the novelty of the theme, scientific contributions addressing LMD in the ODFD industry are still scarce. Though, some very recent papers dealing with the topic may be found, and this highlights that academics are starting to perceive it as noteworthy. Moreover, if considering the perspective of practitioners, the number of consumers who want to order prepared meals online is rapidly increasing, and restaurants need to face this emerging trend if they do not want to irreparably lose customers. Finally, the ODFD business is recently getting the attention of both the public opinion and the press. The working situation of the riders is often debated, and clarifying the economic dynamics behind ODFD could help in getting a clearer view about the theme. As a result, not only academics, but also practitioners and decision makers could benefit from an analysis of the conditions under which last-mile deliveries in the ODFD business are profitable. 
These being the premises, the following research questions were addressed: "What are the economic performances of On-Demand Food Delivery last-mile deliveries? What conditions affect their profitability?"

A key consideration needs to be highlighted about the scope of the work: the research goal is to investigate the profitability of last-mile deliveries for third-party ODFD platforms. This choice delineates the area of the analysis in a threefold direction. First, the work focusses on logistics, and more specifically on last-mile deliveries. Accordingly, it does not aim to provide an evaluation of the overall profitability of ODFD businesses, which would otherwise require to include other analyses and variables - e.g. cost of raw materials (He et al., 2019), people working in the restaurants (Xu and Huang 2019), returns (Mangiaracina et al., 2019), waste management (Giuffrida et al., 2019). Despite logistics is not the only area affecting the results of ODFD initiatives, it represents - as proved by the review of the literature - a key domain to be investigated in this field. Second, the adopted perspective is that of ODFD platforms. This means that the considered revenues and costs are those faced by the platforms, while the analysis of the profitability of the other players - i.e. restaurants and riders - is not in scope. As a matter of fact, literature already presents some work specifically focusing on the perspective of restaurants (e.g. Fauzi, 2019) and riders (e.g. Seghezzi et al., 2020). In addition, on the one hand, restaurants could choose to adhere to ODFD initiatives despite a negative short-term profitability, due to more strategic long-term marketing evaluations (He et al., 2019). On the other hand, according to the work by Seghezzi et al. (2020) - who explicitly took into considerations the perspective of the riders - the working conditions considered in this paper are aligned to positive results in terms of riders' profitability, Third, the considered platforms are third-party ones. They are intermediaries collecting the offer of different restaurants and managing 
the delivery for all of them. They are the most interesting ones to be investigated for both restaurants - which may rely on an online channel without opening an own one and expand their potential customer base - and customers - as they are able to order from a wide array of restaurants through one single app (Karamshetty et al., 2020).

In order to answer the defined research questions, different methodologies have been adopted and combined.

Among them, the work is based on an analytical model, which is representative of a plausible economic structure of last-mile deliveries for a ODFD firm. After its development, it was applied to a realistic context in Milan (Italy). This two-step methodology is widely adopted in academic literature when dealing with crowdsourcing logistics (e.g. Qi et al., 2018). The model was developed and applied relying on the use of spreadsheets, integrated with Google Maps through API for the estimation of distances and the associated travel time. The choice of this tools has a twofold reason. First, the considered delivery problem (in the specific analysed context) is relatively simple if compared to other environments where the delivery density is high, and for which more complex optimisations may be built (e.g. modelling batching/consolidation of orders, allowing the operator to select the most efficient restaurant - among different options - from which the orders can be fulfilled). Second, the model was developed in collaboration with practitioners from the ODFD sector, for whom a simple tool would be more user-friendly and more easily understandable.

Three main methods were adopted to support the model development and application:

- Literature review, aimed at investigating the state of the art of the topic, to set and ground the research objectives in the extant scientific knowledge, and to identify 
useful sparks for the model development and application (e.g. identification of the relevant factors).

- Interviews with practitioners operating in the ODFD business, to both get a clear understanding of the significant variables to be considered (e.g. daily demand and delivery price for the sensitivity analysis), and - similarly to Giuffrida et al. (2019) - to collect data for creating average realistic scenarios to feed the model.

- Analysis of secondary sources (i.e. websites of ODFD service providers, journals for logistics practitioners, reports) to complement information coming from the literature and the interviews (Jick, 1979).

Particular attention was devoted to the role of practitioners (second point of the list). Interviews were performed with three managers working in the three main ODFD companies operating in Italy. The ODFD Italian market is very concentrated: there are about 30 players, but the three major ones are responsible for approximately $90 \%$ of the overall market share (B2c eCommerce Observatory, 2020). As a result, the sample of interviewed practitioners may be considered representative of the overall ODFD Italian scenario. Interviews were performed in three different moments: (i) during the model development, to identify the key variables/parameters, their relations, the main costs; (ii) during the model application - to find reliable data to feed it, as suggested by Mohrman and Lawler (2012); (iii) after the model application, to validate the results of the research. All the three practitioners were interviewed once in each of the three mentioned moments, thus reaching a total of nine interviews. The interviewees were selected based on a twofold criterion. Similarly to Huscroft et al. (2012), first, potential participants were identified among volunteers from previous research efforts and references from senior logistics professionals. Second, practitioners had to belong to the senior management, and not to a specific function (e.g. marketing, logistics); this 
allowed to gain a wider perspective on the ODFD business, avoiding potentially misrepresented or partial views. Based on the two mentioned objectives (i.e. model development/validation and data collection) - in line with Creswell et al. (2004) - two different types of interviews were performed. The interviews aimed to better understand the variables and the relations among them (model development) were performed according to a semi-structured scheme, which allows the rising of ideas and data not previously identified by the authors (Harrell and Bradley, 2009). The interviews aimed to collect quantitative data to feed the model were instead structured, and supported by checklist reporting all the main variables and parameters (Nutting et al., 2002).

Considering the third point of the list (i.e. analysis of secondary sources), two main considerations need to be highlighted. First, the type of consulted sources. Similarly to previous works from the ODFD field (e.g. Raman 2018), they included (i) reports about both the international and the Italian ODFD market, published by research centres (Italian B2C eCommerce observatory) and consulting companies (McKinsey); (ii) articles from both "traditional" (Wired, Forbes) and logistics practitioners-oriented (Logistics Management, Food Logistics) journals; (iii) websites of the main ODFD companies operating in Italy (e.g. Deliveroo, Glovo). The second observation concerns instead the role of these sources in the overall research process. Based on the methodological paper addressing the analysis of secondary sources in logistics by Rabinovich and Cheon (2011), they were used in a twofold way: on the one hand, they were employed in the initial phase of the study; their role was to help comprehending the way ODFD initiatives work, and to reach a better understanding about the main logics behind this business. On the other hand, they were useful to create a first rough version of plausible values for the main variables; in this case, the main goal was to get prepared for the interviews with practitioners and be able to discuss with them eventual 
misalignments to what could be expected. Nonetheless, neither of the interviews which were the actual method used to collect the data - reveal any discrepancy from the hypothesised intervals derived from the reports/articles.

\section{The model}

\subsection{Model structure}

\subsubsection{The model architecture}

The architecture of the model (see Figure 2) is composed by four main building blocks. The corresponding elements were derived while combining the three mentioned methodologies.

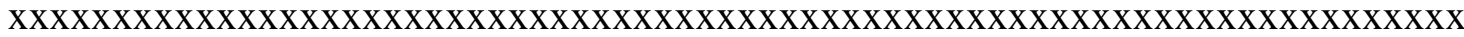

Please take in Figure 2

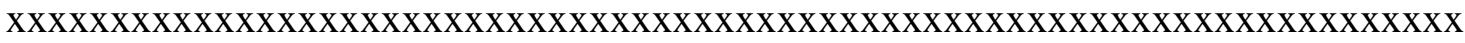

(i) Input data, i.e. the variables describing the last-mile delivery problem, needed to run the model.

- Location of both restaurants and customers: they are the addresses of the points of origin and the points of destination and are needed to compute the distance to be travelled - and then derive the corresponding time required - for each delivery.

- Number of orders: it represents the overall number of daily orders to be fulfilled in the considered area; the algorithm randomly generates orders associated to specific restaurant-customer combinations.

- Delivery price: it is the price customers have to pay to exploit the home delivery service. 
- Commission: it is the fee restaurants have to pay to the ODFD provider in order to benefit from the offered services; it is usually computed as a percentage of the order value. Together with the delivery price, it constitutes the source of income for the ODFD provider.

(ii) Context data, i.e. the parameters describing the application context (e.g. legal constraints, demand characteristics). They may be changed according to the application context considered.

- Demand distribution: it represents the allocation of the orders to the different timeslots; orders are typically not uniformly distributed during the considered time window, but there are some peaks.

- Average order value: it is the average value of an order made by one customer to one restaurant.

- Working shift: it is the minimum number of consecutive hours each rider needs to work. As a matter of fact, riders do typically have to select the slot in which they will work (and thus also the duration of the working shift).

- Service level: it represents the constraint to be met by riders in terms of time performances, i.e. the maximum amount of time a rider can spend to perform the delivery.

- Transport cost per $\mathrm{km}$ : it is the variable cost associated to the used transport mean, which depends on the number of travelled kilometres $(€ / \mathrm{km})$.

- Salary of riders: it is the amount of money paid to the riders for their delivery task. It is composed by two parts: a fixed hourly salary (perceived independently from the number of completed deliveries) and a variable one (proportional to the number of completed deliveries) (Qi et al., 2018). 
(iii) Output data, i.e. the outcomes computed by the model for the considered last-mile delivery problem, given the associated input and context data.

- Total costs: they include the cost for both the rider and the transport mean.

- Revenues: they include the incomes from both the delivery price paid by customers and the commission of the restaurant.

(iv) Model algorithm, i.e. the set of activities and formulas to estimate costs and incomes - and thus the profit - for the ODFD operator performing last-mile deliveries. The process according to which it works is illustrated in the next paragraph (4.1.1).

The model development relies on some assumptions.

First, the application context is the urban one. On the one side, it is the most frequently considered context by literature when tackling crowdsourcing logistics. On the other side, ODFD initiatives are mainly implemented in (usually medium-large) cities.

Second, among the possible alternatives, the selected considered transport mode is the motorcycle.

Third, the time to prepare the meal is considered as fixed. The time constraint to be respected by ODFD operators is related to the shipping phase, and it is computed from the restaurant to the final customer's house.

Fourth, each rider delivers one order at a time (as it usually happens in contexts where the demand is not enough to allow batching): the rider is associated to a restaurant and, once the mission has been completed, he/she must not get back to the point of origin, but is redirected to the closest restaurant that received a subsequent order.

Fifth, only dinner time (from 6 p.m. to 11 p.m.) is examined. In the ODFD business, orders are concentrated in two moments of the day: lunch and dinner. This 
work focuses on the latter, since it is characterised by higher demand, and thus it is the most interesting one for practitioners.

Sixth, no failures in the shipping process are contemplated: customers are supposed to be at home to receive their meal. This is reasonable for on-appointment deliveries in the ODFD sector, whose failure rate is typically negligible.

\subsubsection{The algorithm}

The algorithm works following six main steps, separately performed for each of the different 1-hour timeslots in which the overall dinner time window is divided.

- Order generation: based on the demand distribution along the time window and the location of both restaurants and customers, the orders to be delivered in the timeslot are randomly generated. They correspond to a point of origin (i.e. the address of the restaurant) and to a point of destination (i.e. the address of the customer).

- Time per order estimation: for each single order, the time required to perform the delivery from the restaurant to the customer is computed. This estimation is made based on the real route and the real timing retrieved by Google Maps, which was integrated to the spreadsheet used for the computations through API (Application Programming Interface) keys.

- Order check: each order is then checked; if the time needed to perform the delivery is lower than the maximum imposed by the service level constraint, it is accepted, otherwise it is rejected. This constraint is also considered by real ODFD platforms: based on the selected delivery location, they only allow customers to issue orders from restaurants that are close enough to grant an acceptable delivery time.

- Computation of the number of riders needed:

- first, a theoretical number of needed riders is computed for each timeslot, based on the overall number of orders to be delivered. 
- Second, the actual number of riders to be hired for each timeslot is defined. It may often happen that the actual number of riders is higher that the theoretical one. As a matter of fact, even if a rider is needed just for one timeslot, he/she has to be hired for the whole duration of a shift.

- Orders-riders allocation: based on the orders to be delivered and the number of riders for the timeslot, the algorithm allocates each specific order to a specific rider, according to the process shown in Figure 3.

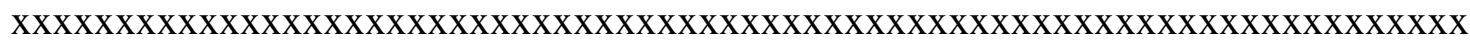

Please take in Figure 3

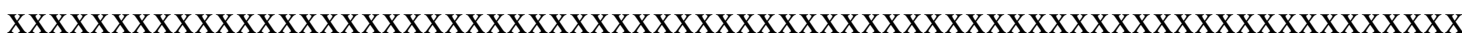

First, one order is assigned to all the riders, and the related travel time per rider is computed. Then, the algorithm selects the "most available" rider, i.e. the rider whose total travelling time (the time for performing the assigned delivery) is the lowest: he/she will be assigned the next order. This order has to come from the restaurant that is the closest to his/her current location (for efficiency reasons). Therefore, the distances of the rider from all the candidate restaurants are computed, and the minimum one is selected. The order from the closest restaurant is thus allocated to the rider, whose travel time value is updated including the time required to both reach the restaurant and perform the delivery. Then, the algorithm checks whether there are still not-assigned orders. If there are, the cycle begins again with the selection of the next available rider. Otherwise, the allocation for that time slot is completed. 
- Total time and distances computation: once all the orders have been allocated, the algorithm then computes both the actual time spent by the riders and the distance travelled to perform the deliveries in the considered timeslot.

- Profit estimation: based on the obtained results, the algorithm estimates the profit associated to last-mile deliveries in the considered timeslot, based on the incomes and the costs. More in detail, it considers: the incomes from the delivery price paid by customers, the incomes from the commission withheld by the platforms from the restaurants and the variable salary of the riders (that all depend on the overall number of orders), the fixed salary (proportional to the number of hired riders) and the cost for the transport mean (depending on the travelled distance).

Once all the six steps have been performed for all the different timeslots, the overall daily profit may then be derived while summing up the values referred to the different slots.

\subsection{Model application}

The model was applied to a realistic context, i.e. Porta Garibaldi area in Milan (Italy). More in detail, first it was applied to a base case scenario (for which 20 applications were performed) and then some sensitivity analyses were performed on relevant parameters (through 220 additional applications). For both the analyses, values describing the reference representative scenario were derived based on the data collected through interviews with practitioners (in line with other works, e.g. Giuffrida et al. (2019)). Moreover, to complete and double check the associated values, two additional methodologies were adopted, namely literature review and analysis of secondary sources. 


\subsubsection{Base case application}

The main considered inputs and context data are shown in Table 1.

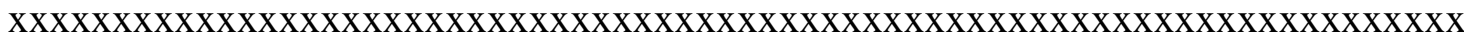 Please take in Table 1 \\ XXXXXXXXXXXXXXXXXXXXXXXXXXXXXXXXXXXXXXXXXXXXXXXXXXXXXXXXXXXXXXXXXXXXXX}

Some clarifications should be given for three of the mentioned items: the location of restaurants/customers, the delivery price and the demand distribution.

Concerning the points of origin and destination, 15 locations were considered for restaurants and 150 for customers. These are potential locations, among which the algorithm randomly selects those corresponding to the different orders. As a consequence, the density of those points does thus not correspond to the actual delivery density (which instead depends on the overall daily demand).

Concerning the delivery price, it is a strategic and critical variable, whose value may significantly change depending on both ODFD providers and cities (Yeo et al., 2017). Hence, not only one, but four different values were considered for the base case scenario, namely 0 (i.e. free delivery, for which the customer does not have to pay), 1, 2 and $3 € /$ delivery.

Considering eventually the demand distribution, the overall number of daily orders was supposed to be scattered along the evening time window according to the percentages shown in Table 2. The slot with the highest number of requests is the one from 8 to 9 p.m., followed by that from 9 to 10 p.m. and that from 7 to 8 p.m.. 
The model was applied, based on the illustrated data and under the considered assumptions. More in detail, to provide more reliable results, five different applications were performed for each of the four considered price policies (thus running 20 applications). The stemming results are shown in Figure 4.

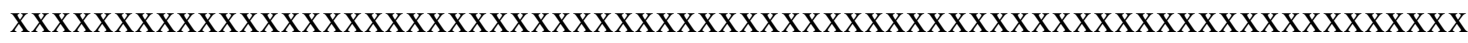
Please take in Figure 4

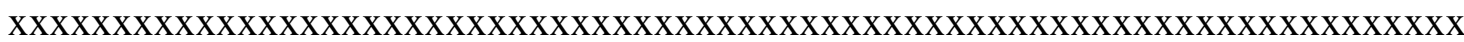
According to these results, in the base case scenario, the threshold for a company operating in the ODFD business to be profitable corresponds to a delivery price of $1 €$ per delivery. Considering the highest price of the $3 € /$ delivery-scenario, the profit reaches $363 € /$ day. On the other side, despite the commission paid by the restaurant, free deliveries would not allow ODFD operators to repay the costs they have to bear ( $220 € /$ day loss in the worst case of the free delivery scenario). As a result, two main considerations may be derived. First, offering free delivery is not economically sustainable for platforms. This could be considered as a marketing lever to rely on in order to attract customers, but cannot be pursued in the long term. Second, the positive relation between the average daily profit and the delivery price seems to be linear. Also in this case, wise marketing analyses should be performed in order to evaluate the effect of the delivery price on the purchasing intention of customers, to accordingly set successful strategies. 


\subsubsection{Sensitivity analysis}

To test the reliability of the model and the robustness of the results, a sensitivity analysis was performed on two input parameters, namely the number of orders and the salary of the riders (intended as fixed salary, variable salary and their combination).

The reason behind the choice of these two parameters is threefold. On the one side, the values of different parameters were varied during the model application, and the two selected ones appeared to be those impacting the most on profitability performances. On the other side, interviewed practitioners agreed with this choice. Finally, they were selected based on the literature. Considering the demand, it is expected to improve delivery efficiency, due to its positive effect in increasing the delivery density (Boyer et al., 2009; Gevaers et al., 2014). Considering the salary of the riders in the field of crowdsourcing logistics, since there is no agreement among the authors about whether it is better to only consider a variable component (Chen et al., 2018), a fixed component (Kafle et al., 2017) or both (Qi et al., 2018), it is interesting to deepen the effect of variations of both these variables.

First, the number of daily orders was varied to evaluate the impact of a different demand on the profitability of ODFD last-mile deliveries. More in detail, beside the base scenario (180 daily orders), three additional cases were analysed, namely 90, 270 and 360 daily orders, and 5 applications were run for each case.

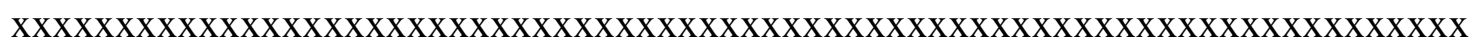
Please take in Figure 5

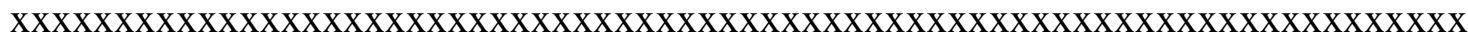

Results (Figure 5) show the average among the five profit values for each demand case and for all the four delivery price options. Two main conclusions may be drawn. First, 
the same delivery price - i.e. $1 € /$ delivery - may be considered the critical value to make ODFD business profitable, no matter the value of the daily demand. Second, differently from expectations, a higher demand does not only improve profitable situations, but it also worsens loss situations. As a matter of fact, it amplifies the results that would be obtained with lower demand values, no matter if they are positive or negative. This could be due the main difference between traditional $\mathrm{B} 2 \mathrm{C}$ deliveries and deliveries in the ODFD business. In traditional delivery tours, both the cost of the driver and part of the cost of the transport mean do not depend on the number of deliveries, but on the number of daily working hours. Accordingly, if the overall daily cost is allocated to a higher demand (i.e. to a higher number of deliveries), the cost per delivery decreases. This does not happen in ODFD, where each order corresponds to one delivery tour (Zambetti et al., 2017): increasing the number of destinations does not mean decreasing the share of the total cost per delivery, but adding new delivery tours. This would not be the same if ODFD orders were batched: in that case grouping different orders and assigning them to the same rider would allow to increase the delivery density, thus having a positive effect on profitability performances.

The second set of runs in the sensitivity analysis was performed varying the salary of the riders. At first - keeping a $1.5 € /$ delivery variable wage - the fixed salary was varied in a range between 5 and $12 € /$ hour. The analysis, consisting in five applications, was replicated for each of the four delivery price options and for each of the four daily demand values. Then - keeping an $8 € /$ hours fixed wage - the variable wage was varied in a range between 0 and $3 € /$ delivery. Also in this case, the analysis consisting in five applications - was replicated for each of the four delivery price options and for each of the four daily demand values. Finally, after having individually analysed the two components of the salary, both were concurrently varied. More in 
detail, three representative combinations - chosen based on interviews with practitioners - were considered in addition to the base one (Table 3).

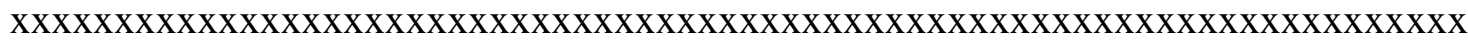

Please take in Table 3

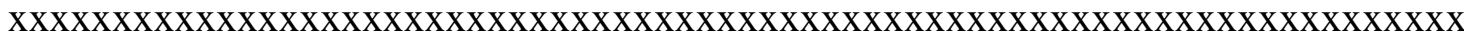

Figure 6 shows the results of the analyses derived from the combined variation of both fixed and variable salary, in case the delivery price paid by customers is set to $0 € /$ delivery, $1 € /$ delivery, $2 € /$ delivery and $3 € /$ delivery respectively.

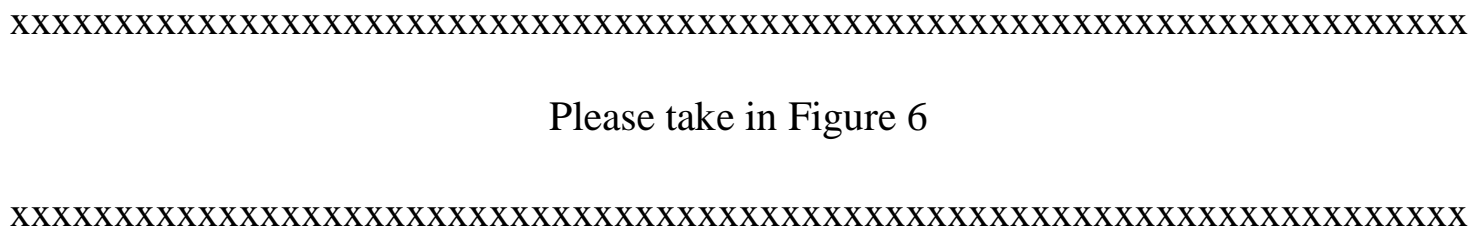

These analyses show how, for all the delivery prices, it is more effective for companies to increase the variable component of the salary reducing the fixed one, thus paying the riders based on the number of accomplished deliveries. Though, this type of remuneration may imply "social" issues, and in some countries it is not allowed due to legal constraints.

Overall, the sensitivity analysis shows that the results are consistent with those obtained in the base case. Moreover, they allow to draw some general considerations about the possible scenarios. The best configuration in terms of profitability corresponds to: fixed salary $0 € / \mathrm{h}$, variable wage $3 € /$ delivery, delivery price $3 €$ and number of daily orders 360 . In this case, the company is able to achieve a total profit of $1,410 € /$ day on the considered area. On the contrary, the worst scenario is characterized 
by: fixed salary $12 € / \mathrm{h}$, variable wage $1.5 € /$ delivery, free delivery (delivery price $0 €$ ) and 360 daily orders. In this setting, the delivery platform is not able to economically sustain itself recording a loss of $966 € /$ day. Beside the specific results, the analysis is useful to define the most suitable mix between fixed and variable wages, and this is particularly relevant in cases in which legal constraints do not allow to pay riders only based on the accomplished deliveries.

\section{Conclusions}

The spread of ODFD initiatives has opened new research questions in the last-mile delivery context, whose answers are still not consolidated neither in the scientific literature nor in the managerial context, particularly if considering contexts in which the ODFD is still not a widespread and stable phenomenon. This paper reached the defined research goal, while developing and applying a model for evaluating the profitability conditions of last-mile deliveries in the ODFD business. The most impacting variables were identified and the related critical values for the business profitability were analysed. In addition, the sensitivity analysis on the critical variables (i.e. daily demand, salary of the rider) allowed to draw interesting insights about their effect on profitability.

This work may lead to implications for academics, practitioners and decision makers. On the academic side, it enhances extant scientific knowledge about logistics in the ODFD business, proposing a model to evaluate costs and incomes of the last-mile delivery phase and to assess the impact that variations in significant variables may have on them. On the managerial side, this work can provide support for practitioners operating in the ODFD industry, since it allows to identify under which conditions profitability can be achieved and to analyse how profitability changes if varying specific choices or context parameters. More in detail, it could be useful to: (i) practitioners of 
ODFD platforms - from both the logistics and marketing fields - to make strategic decisions, e.g. set the delivery price (Yeo et al., 2017); (ii) managers of restaurants, to set evaluations about the price to be proposed to take-away customers if compared to “traditional" ones (Xu and Huang, 2019). In addition, legislators could benefit from the developed analysis in order to rely on quantitative results in evaluating the effects of alternative actions they may implement. Considering for instance labour regulations (e.g. forcing ODFD platforms to hire riders as traditional employees), they may have a strong impact on both the salary (type and amount of remuneration) and the working shifts of the riders. The model could help in evaluating the effects of these decisions on the business profitability.

The main limitations of the work are linked to the hypotheses considered in the application of the model, i.e. a specific geographical area (Milan Porta Garibaldi), timeslots (evening hours) and transport mode (motorbike). Though, further developments could solve these issues both changing the area and enlarging the time windows, and contemplating also alternative transport modes (e.g. car, bicycle). The model is very flexible and adaptable in terms of both input variables and context parameters - which can be varied according to the considered last-mile delivery problem and scenario - and it is thus suitable to analyse additional contexts that are different from those addressed in this work. Besides, the work focuses on point-to-point deliveries, without considering the possibility to create batches of orders. This makes it suitable for context in which ODFD is still at embryonal phases, and characterised by low delivery density. In addition, while in the model delivery price and demand variations are separately considered, it could be useful to evaluate and integrate an eventual relation between the delivery price and the demand (thus also taking into considerations potential variations of the average order value). Finally, as stated in the 
section devoted to the objectives of the work, the focus is on last-mile deliveries from the perspective of ODFD platforms. Other papers could enhance the obtained results while considering other elements affecting the overall profitability (e.g. cost of raw materials, cost of people employed in the restaurants) or the perspective of the other actors of the system (e.g. riders and restaurants).

\section{References}

Allen, B. J., Chandrasekaran, D., and Basuroy, S. (2018), "Design crowdsourcing: The impact on new product performance of sourcing design solutions from the “crowd”", Journal of Marketing, Vol. 82 No. 2, pp. 106-123

Arslan, A. M., N. Agatz, L. Kroon, and Zuidwijk, R. (2018), “Crowdsourced Delivery -A Dynamic Pickup and Delivery Problem with Ad Hoc Drivers", Transportation Science.

Boyer, K.K., Prud'homme, A.M., and Chung, W. (2009), “The Last Mile Challenge: Evaluating the Effects of Customer Density and Delivery Window Patterns", Journal of Business Logistics, Vol. 30 No. 1, pp. 185-201.

Boysen, N., S. Schwerdfeger, and Weidinger, F. (2018), "Scheduling last-mile deliveries with truck-based autonomous robots", European Journal of Operational Research, Vol. 271 No. 3, pp. 1085-1099.

Brown, S. (1987), "Institutional change in retailing: a review and synthesis.”, European journal of marketing, Vol. 21 No. 6, pp. 5-36.

Carbone, V., Rouquet, A., and Roussat, C. (2017), "The Rise of Crowd Logistics: A New Way to Co-Create Logistics Value”, Journal of Business Logistics, Vol. 38 No. 4, pp. 238-252.

Chen, C., D. Zhang, L. Wang, Ma, X., Han, X., and Sha, E. (2014), “TaxiExp : A Novel Framework for City-wide Package Express Shipping via Taxi CrowdSourcing”, IEEE International Conference on Ubiquitous Intelligence and Computing, Bali, December, pp. 244-251.

Chen, W., Mes, M. and Schutten M. (2018), "Multi-hop driver-parcel matching problem with time windows", Flexible Services and Manufacturing Journal, Vol. 30 No.3, pp. 517-553. 
Creswell, J. W., Fetters, M. D., \& Ivankova, N. V. (2004), “Designing a mixed methods study in primary care", The Annals of Family Medicine, Vol. 2 No. 1, pp. 7-12.

Esper, T. L., Jensen, T. D., Turnipseed, F. L., and Burton, S. (2003), “The last mile: an examination of effects of online retail delivery strategies on consumers", Journal of Business logistics, Vol. 24 No. 2, pp. 177-203.

Fauzi, A. A. (2019), “Critical Factors on Sme Managers' Adoption of Online Delivery Service Application", International Journal of Business and Society, Vol. 20 No. 3, pp. 1130-1148.

Fernie, J., Sparks, L. and McKinnon, A. C. (2010), "Retail logistics in the UK: past, present and future", International Journal of Retail \& Distribution Management, Vol. 38 No. 11/12, pp. 894-914

Fikar, C., Hirsch, P., and Gronalt, M. (2018), “A decision support system to investigate dynamic last-mile distribution facilitating cargo-bikes", International Journal of Logistics Research and Applications, Vol. 21 No.3, pp. 300-317.

Fleming, P. (2017), "The human capital hoax: Work, debt and insecurity in the era of Uberization”, Organization Studies, Vol. 38 No. 5, pp. 691-709.

Gevaers, R., Van de Voorde, E. and Vanelslander, T. (2011), "Characteristics and Typology of Last-mile Logistics from an Innovation Perspective in an Urban Context", City Distribution and Urban Freight Transport, Edward Elgar Publishing.

Ghose, A., Ipeirotis, P. G., and Li, B. (2012), "Designing ranking systems for hotels on travel search engines by mining user-generated and crowdsourced content", Marketing Science, Vol. 31 No. 3, pp. 493-520.

Giuffrida, M., Mangiaracina, R., Miragliotta, G., Perotti, S., and Tumino, A. (2019), "Modelling the environmental impact of omni-channel purchasing in the apparel industry: the role of logistics", International Journal of Logistics Systems and Management, Vol. 34 No. 4, pp. 431-456.

Grewal, D., Iyer, G. R., and Levy, M. (2004), “Internet retailing: enablers, limiters and market consequences", Journal of business research, Vol. 57 No. 7, pp. 703713.

Ha, Q. M., Deville, Y., Pham, Q. D., and Hà, M. H. (2018), “On the min-cost traveling salesman problem with drone", Transportation Research Part C: Emerging Technologies, Vol. 86, pp. 597-621. 
Harrell, M. C., and Bradley, M. A. (2009), "Data collection methods. Semi-structured interviews and focus groups", Rand National Defense Research Inst santa monica ca.

He, Z., Han, G., Cheng, T. C. E., Fan, B., and Dong, J. (2019), "Evolutionary food quality and location strategies for restaurants in competitive online-to-offline food ordering and delivery markets: An agent-based approach", International Journal of Production Economics, Vol. 215, pp. 61-72.

Hollander, S. C. (1960), “The wheel of retailing”, Journal of Marketing, Vol. 25 No. 1, pp. 37-42.

Hübner, A., Kuhn, H., and Wollenburg, J. (2016), "Last mile fulfilment and distribution in omni-channel grocery retailing: A strategic planning framework", International Journal of Retail \& Distribution Management, Vol. 44 No. 3, pp. 228-247.

Huddleston, P., Whipple, J., Mattick, R. N., and Lee, S. J. (2009), “Customer satisfaction in food retailing: comparing specialty and conventional grocery stores”, International Journal of Retail \& Distribution Management, Vol. 37 No. 1, pp. 63-80.

Huscroft, J. R., Hazen, B. T., Hall, D. J., Skipper, J. B., and Hanna, J. B. (2013). Reverse logistics: past research, current management issues, and future directions. The International Journal of Logistics Management, Vol. 24 No. 3, pp. 304-327.

Jick, T. D. (1979), "Mixing qualitative and quantitative methods: Triangulation in action”, Administrative Science Quarterly, Vol. 24 No. 4, pp. 602-611.

Kafle, N., Zou B., and Lin J. (2017), "Design and modeling of a crowdsource-enabled system for urban parcel relay and delivery", Transportation Research Part B: Methodological, Vol. 99, pp. 62-82.

Kapoor, A. P., and Vij, M. (2018), “Technology at the dinner table: Ordering food online through mobile apps", Journal of Retailing and Consumer Services, Vol. 43, pp. 342-351.

Karamshetty, V., Freeman, M., and Hasija, S. (2020), “An Unintended Consequence of Platform Dependence: Empirical Evidence from Food-Delivery Platforms" (August 5, 2020). INSEAD Working Paper No. 2020/35/TOM, 
Kleemann, F., Voß, G. G., and Rieder, K. (2008), "Un (der) paid innovators: The commercial utilization of consumer work through crowdsourcing", Science, technology \& innovation studies, Vol. 4 No. 1, pp. 5-26.

Klumpp, M., and Ruiner, C. (2018), "Digitalization and Work Organization in New Urban Food Delivery Systems", Proceedings in Food System Dynamics, pp. 301-312.

Lim, S. F. W., Jin, X., and Srai, J. S. (2018), “Consumer-driven e-commerce: A literature review, design framework, and research agenda on last-mile logistics models", International Journal of Physical Distribution and Logistics Management, Vol. 48 No. 3, pp. 308-332.

Macioszek, E. (2017), "First and Last Mile Delivery-Problems and Issues", Scientific And Technical Conference Transport Systems Theory And Practice, pp. 147154. Springer, Cham.

Mangiaracina, R., A. Perego, A. Seghezzi, and Tumino, A. (2019), "Innovative Solutions to Increase Last-Mile Delivery Efficiency in B2C e-Commerce: a Literature Review.” International Journal of Physical Distribution \& Logistics Management, Vol. 49 No. 9, pp. 901-920

Markin, R. J., and Duncan, C. P. (1981), “The transformation of retailing institutions: Beyond the wheel of retailing and life cycle theories", Journal of Macromarketing, Vol. No. 1, pp. 58-66.

Nutting, P. A., Rost, K., Dickinson, M., Werner, J. J., Dickinson, P., Smith, J. L., and Gallovic, B. (2002), "Barriers to initiating depression treatment in primary care practice", Journal of General Internal Medicine, Vol. 17 No. 2, pp. 103-111.

Qi, W., Li, L., Liu, S., and Shen Z.J.M. (2018), "Shared Mobility for Last-Mile Delivery: Design, Operational Prescriptions and Environmental Impact”, Manufacturing \& Service Operations Management, Vol. 20 No. 4, pp. 601-800.

Rabinovich, E., and Cheon, S. (2011), "Expanding horizons and deepening understanding via the use of secondary data sources", Journal of Business Logistics, Vol. 32 No. 4, pp. 303-316.

Rai, H. B., Verlinde, S., Merckx, J., and Macharis, C. (2017), "Crowd logistics: an opportunity for more sustainable urban freight transport?", European Transport Research Review, Vol. 9 No. 3, pp. 39. 
Raman, P. (2018). Zomato: a shining armour in the foodtech sector. Journal of Information Technology Case and Application Research, Vol. 20 No. 3-4, pp. 130-150.

Reyes, D., Savelsbergh, M., and Toriello, A. (2017), "Vehicle routing with roaming delivery locations", Transportation Research Part C: Emerging Technologies, Vol. 80, pp. 71-91.

Roth, V. J., and Klein, S. (1993), "A theory of retail change", International Review of Retail, Distribution and Consumer Research, Vol. 3 No. 2, pp. 167-183.

Rougès, J.-F., and Montreuil, B. (2014), “Crowdsourcing delivery: New interconnected business models to reinvent delivery", 1st International Physical Internet Conference, pp. 28-30.

Osservatorio eCommerce B2c (2019), "L’eCommerce B2c:il motore di crescita e innovazione del Retail!" [http://www.osservatori.net].

Osservatorio eCommerce B2c (2020), "Food\&Grocery... Ora l'online è di casa!" [http://www.osservatori.net].

Schreieck, M., Pflügler, C., Dehner, C., Vaidya, S., Bönisch, S., Wiesche, M., and Krcmar, H. (2016), “A Concept of Crowdsourced Delivery for Small Local Shops", Lecture Notes in Informatics (LNI).

Sheth, J. (2020). The future of retailing: When the artificial becomes real.

Seghezzi, A., Mangiaracina, R., Tumino, A., \& Perego, A. (2020). 'Pony express' crowdsourcing logistics for last-mile delivery in $\mathrm{B} 2 \mathrm{C}$ e-commerce: an economic analysis. International Journal of Logistics Research and Applications, pp. 1-17.

Singh, R. (2019), "Why do online grocery shoppers switch or stay? An exploratory analysis of consumers' response to online grocery shopping experience", International Journal of Retail \& Distribution Management.

Slabinac M. (2015), "Innovative solutions for a last-mile delivery - A European experience", 15th International Scientific Conference Business Logistics in Modern Management, Osijek, October, pp. 111-130.

Vanelslander, T., Deketele, L., and Van Hove, D. (2013), “Commonly used ecommerce supply chains for fast moving consumer goods: comparison and suggestions for improvement", International Journal of Logistics Research and Applications, Vol. 16 No. 3, pp. 243- 256.

Vecera, R., and O. Pribyl. (2017), "Key denominators of success in crowdsourced logistics”, Smart City Symposium Prague (SCSP), Prague, May 1-5. 
Xiao, Z., Wang, J. J., \& Liu, Q. (2018), “The impacts of final delivery solutions on eshopping usage behaviour: The case of Shenzhen, China", International Journal of Retail and Distribution Management, Vol. 46 No. 1, pp. 2-20.

Wang, X., Zhan, L., Ruan, J., and Zhang, J. (2014), "How to choose "last mile" delivery modes for E-fulfillment", Mathematical Problems in Engineering.

Wang, Y., D. Zhang, Q. Liu, F. Shen, and L.H. Lee. (2016), "Towards enhancing the last-mile delivery: An effective crowd- tasking model with scalable solution", Transportation Research Part E: Logistics and Transportation Review Vol. 93, pp. 279-293.

Wu, J., Kim, A. J., Chen, L., and Johnson, K. K. (2017), “Attitudes toward crowdsourced, community-involved new product development", Journal of Fashion Marketing and Management, Vol. 21 No. 4, pp. 453-467.

Xiao, Z., Wang, J. J., \& Liu, Q. (2018), “The impacts of final delivery solutions on eshopping usage behaviour", International Journal of Retail \& Distribution Management.

Xu, X., \& Huang, Y. (2019), “Restaurant information cues, Diners' expectations, and need for cognition: Experimental studies of online-to-offline mobile food ordering”, Journal of Retailing and Consumer Services, Vol. 51, pp. 231-241.

Yang, Z., Peterson, R. T., and Cai, S. (2003), "Services quality dimensions of Internet retailing: an exploratory analysis", Journal of services marketing, Vol. 17 No. 7, pp. 685-700.

Yeo, V. C. S., Goh, S. K., \& Rezaei, S. (2017), “Consumer experiences, attitude and behavioral intention toward online food delivery (OODFD) services", Journal of Retailing and Consumer Services, Vol. 35, pp. 150-162.

Zambetti, M., A. Lagorio, and R. Pinto. (2017), “A network design model for food ordering and delivery services", XXII Summer School Francesco Turco, Palermo, September, pp. 1-7. 


\begin{tabular}{|c|c|c|}
\hline \multirow{3}{*}{$\underset{\frac{0}{3}}{\frac{0}{3}}$} & Number of orders & 180 orders/day \\
\hline & Delivery price & $0-1-2-3 € /$ delivery \\
\hline & Commission & $15 \%$ \\
\hline \multirow{6}{*}{ 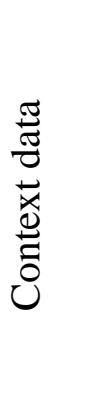 } & Demand distribution & See Table 2 \\
\hline & Average order value & $30 € /$ order \\
\hline & Working shift & 4 hours \\
\hline & Service level & 15 minutes \\
\hline & Transport cost per km & $0.036 € / \mathrm{km}$ \\
\hline & Salary of riders & $8 € /$ hour $+1.5 € /$ delivery \\
\hline
\end{tabular}

Table 1: Input and context data

\begin{tabular}{|c|c|}
\hline Time window & \% orders \\
\hline $6-7$ (p.m.) & $5 \%$ \\
\hline $7-8$ (p.m.) & $18 \%$ \\
\hline $8-9$ (p.m.) & $36 \%$ \\
\hline $9-10$ (p.m.) & $28 \%$ \\
\hline $10-11$ (p.m.) & $8 \%$ \\
\hline $11-12$ (p.m.) & $5 \%$ \\
\hline
\end{tabular}

Table 2: Demand distribution

\begin{tabular}{|c|c|c|}
\hline & Fixed salary & Variable salary \\
\hline Case 0 & $8 € /$ hour & $1.5 € /$ delivery \\
\hline Case 1 & $0 € /$ hour & $3 € /$ delivery \\
\hline Case 2 & $4 € /$ hour & $2 € /$ delivery \\
\hline Case 3 & $12 € /$ hour & $0 € /$ delivery \\
\hline
\end{tabular}

Table 3: Salary variations 


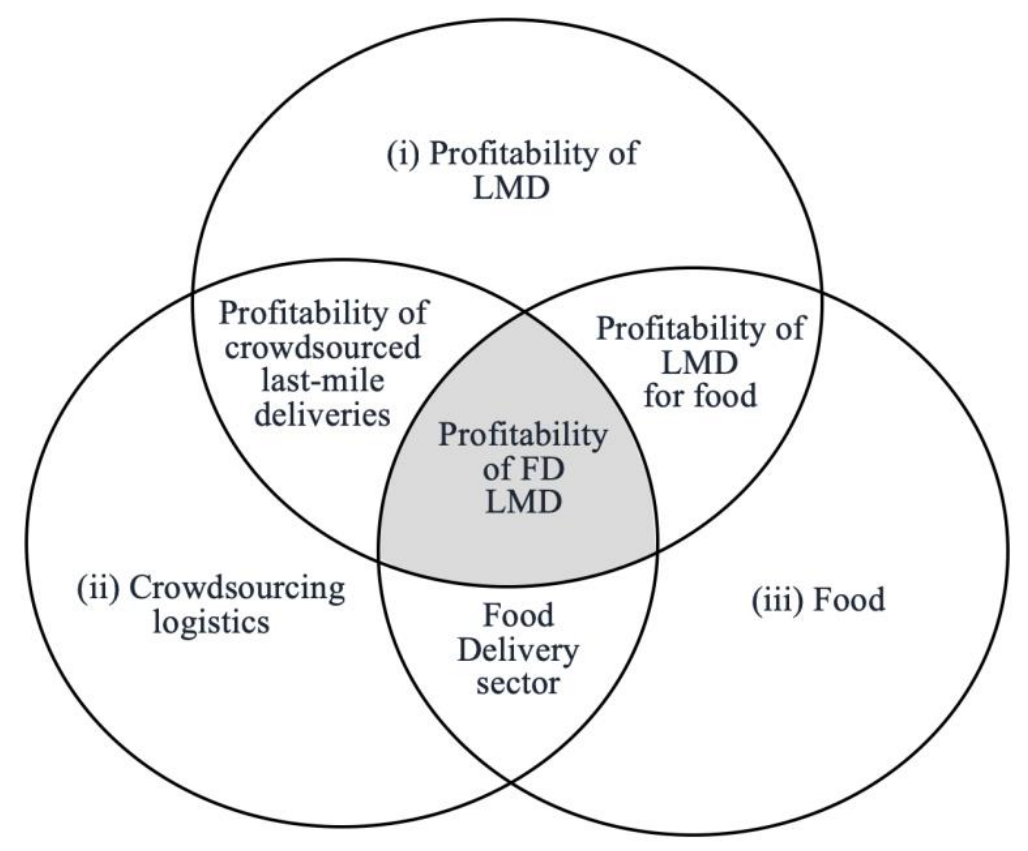

Figure 1

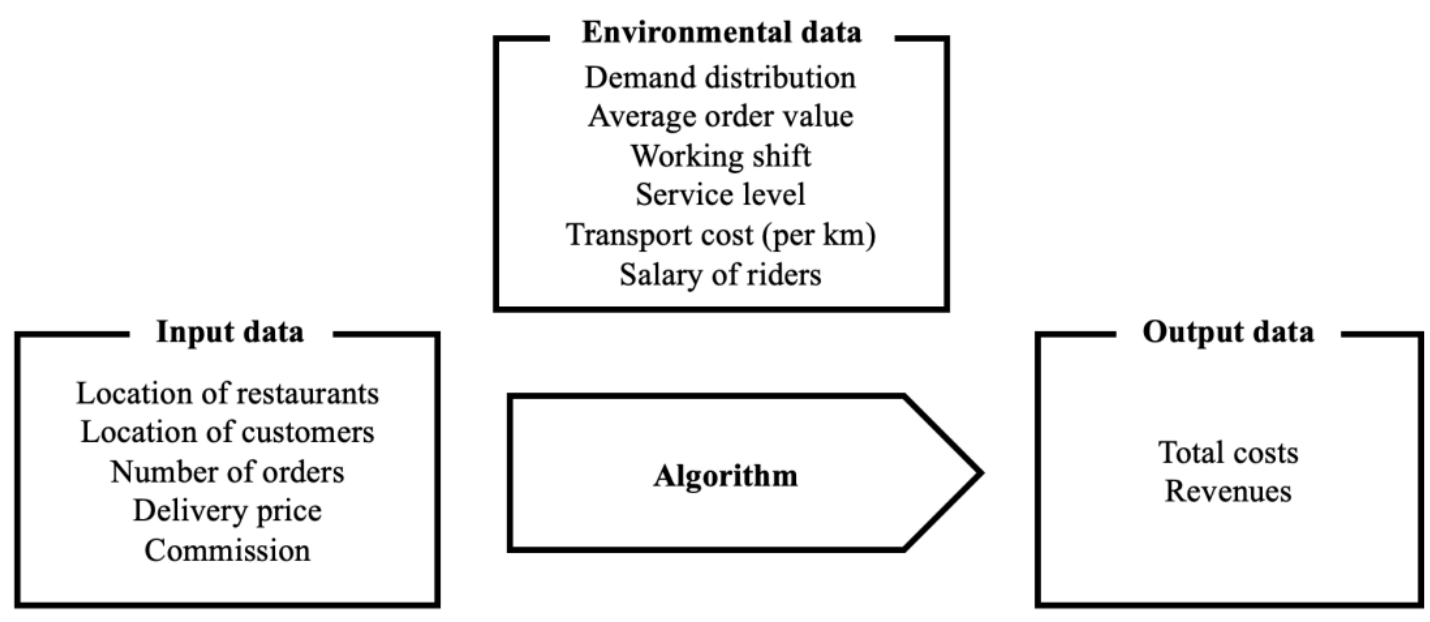

Figure 2 
$1^{\text {st }}$ order assigned to each rider, and travel time computed

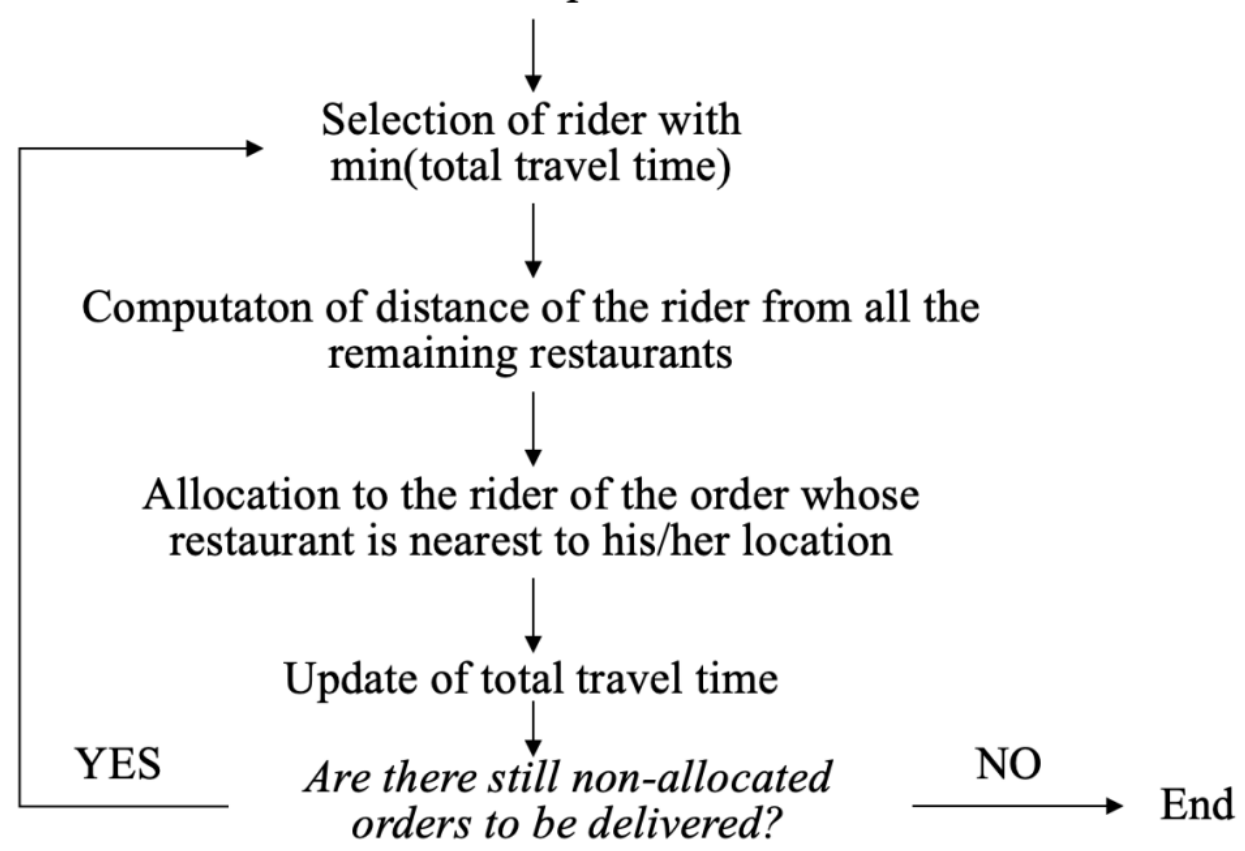

Figure 3

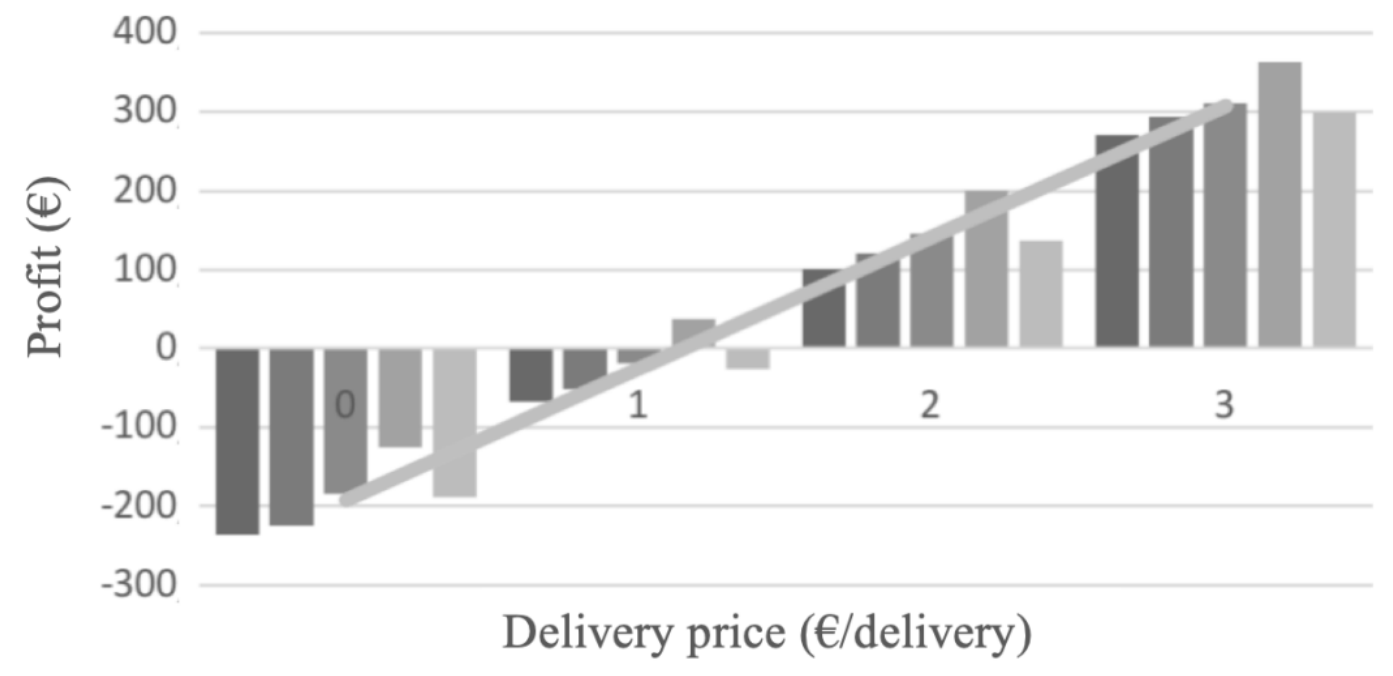

Figure 4 


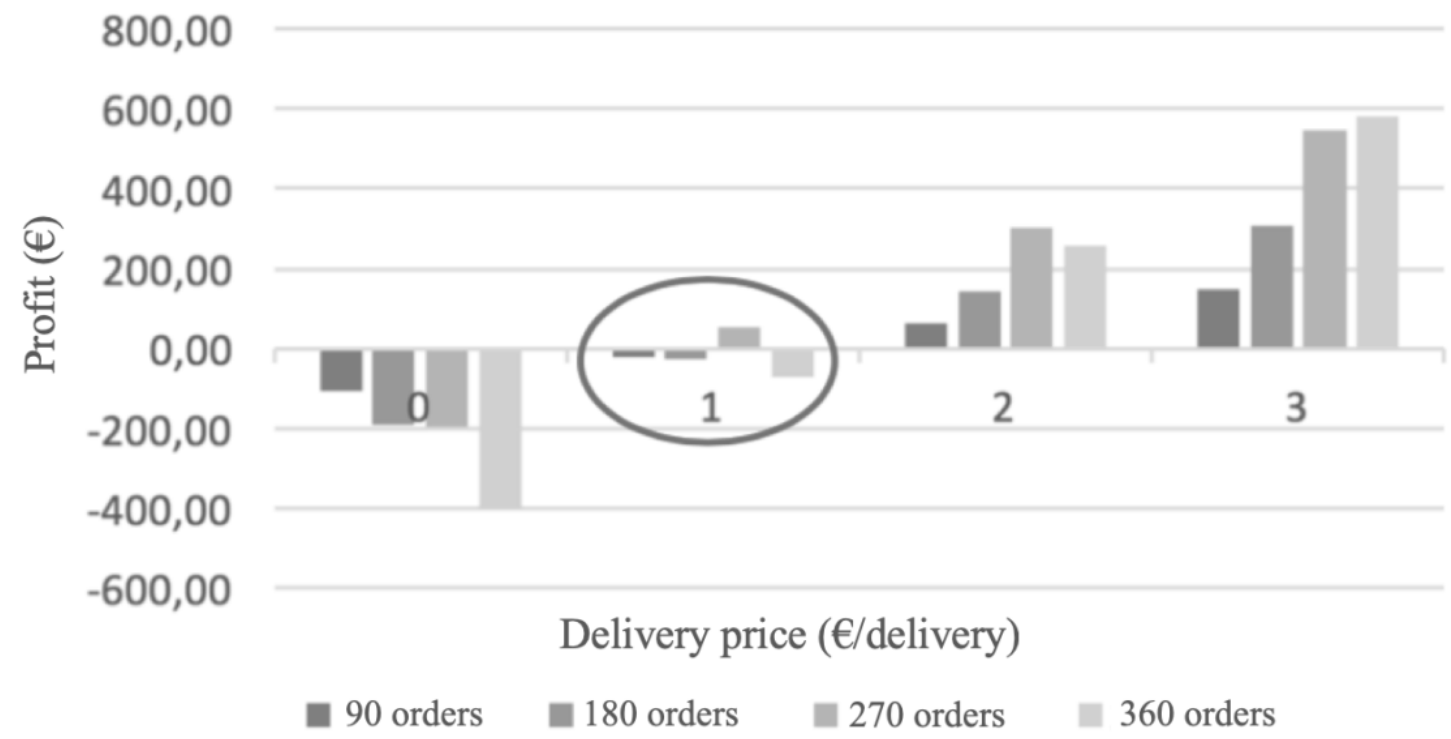

Fugure 5

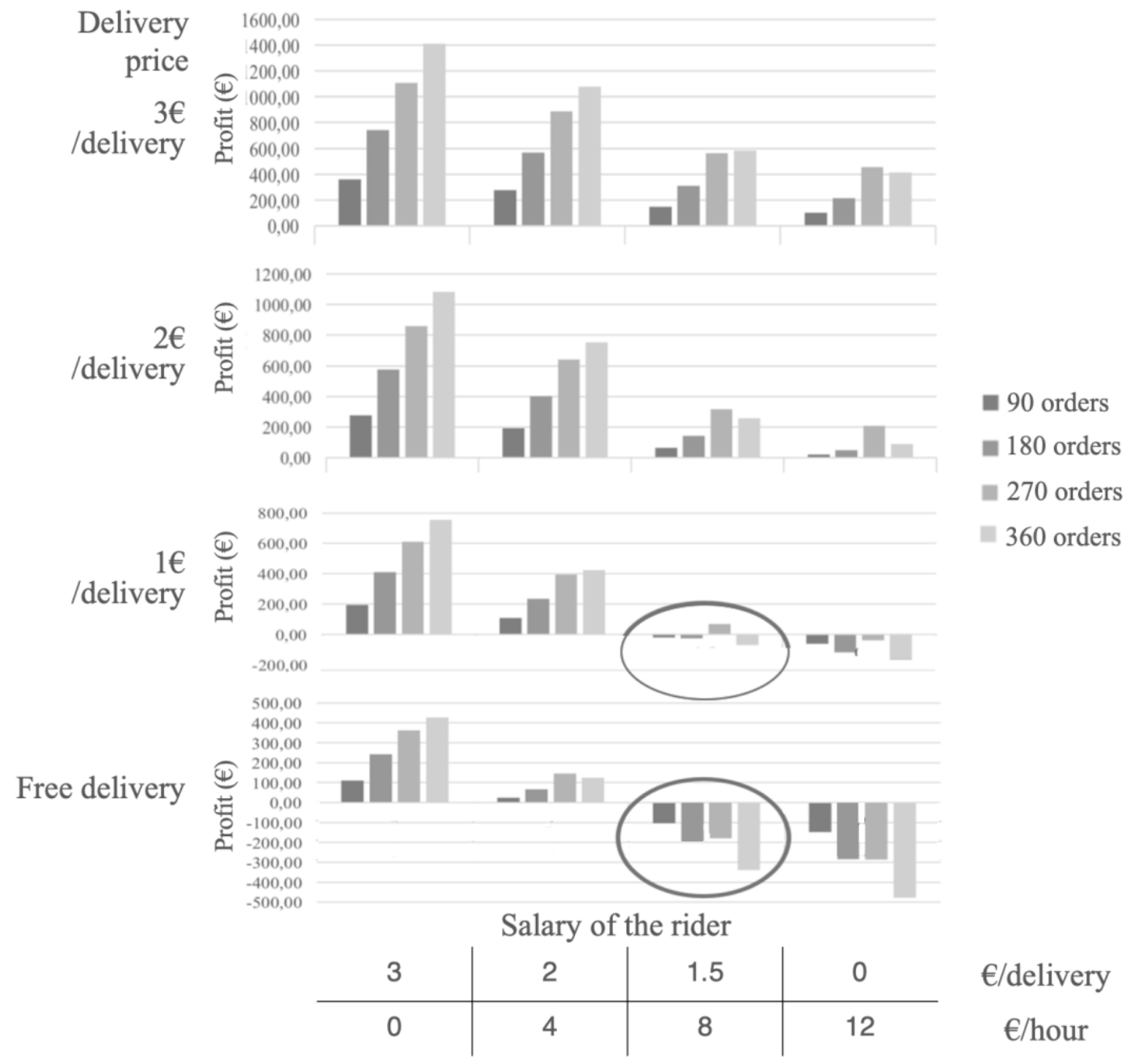

Figure 6 